\title{
Cyclopolymerization of $N$-Alkyl- $N$-allylacrylamides
}

\author{
Wakichi Fukuda, Atsushi TAKAhashi, Yuji TAKenAKA, \\ and Hiroshi KAKIUCHI \\ Department of Applied Chemistry, Faculty of Engineering, \\ Yokohama National University, Hodogaya-ku, \\ Yokohama 240, Japan
}

(Received August 21, 1987)

\begin{abstract}
Free-radical polymerization of $N$-alkyl- $N$-allylacrylamides, where $N$-alkyl substituents were $N$-methyl, $N$-butyl, and $N$-octyl, was carried out with $\alpha, \alpha^{\prime}$-azobisisobutyronitrile (AIBN) at $60^{\circ} \mathrm{C}$. Soluble polymers were prepared when the extent of conversion was low or even high in the polymerization with low monomer concentration. Residual carbon-carbon double bonds in the polymers were determined by both spectroscopic and titrimetric methods to be only allyl groups. The degree of cyclization increased either with decrease in the monomer concentration or increase in the chain length of $\mathrm{N}$-alkyl groups. A suggested mechanism of cyclopolymerization includes: (1) the propagating radicals add intermolecularly to the acryloyl group of monomers; (2) there are two conformational isomers in the propagating acryloyl radicals relating to $\mathrm{C}(=\mathrm{O})-\mathrm{N}$ bond; (3) the $\mathrm{C}(=\mathrm{O})-\mathrm{N}$-trans-allyl isomer, where the acryloyl radical and the allyl group are located on the same side of the $\mathrm{C}(=\mathrm{O})-\mathrm{N}$ bond, is exclusively cyclized to give 5-membered ring unit; (4) the fraction of the $\mathrm{C}(=\mathrm{O})-\mathrm{N}$-trans-allyl isomer increases with the chain length of $\mathrm{N}$-alkyl groups, and (5) the rate of isomerization of the $\mathrm{C}(=\mathrm{O})-\mathrm{N}$-cis-allyl isomer to the trans one is slow enough to permit intermolecular propagation reactions. Copolymerization of mono-olefins having each counterpart of dienes was also carried out to give the copolymers mainly containing the acryloyl monomers.
\end{abstract}

KEY WORDS Cyclopolymerization / N-Methyl- $N$-allylacrylamide / NButyl- $N$-allylacrylamide / N-Octyl- $N$-allylacrylamide $/ N$-Alkyl- $N$-allylacrylamide / Unconjugated Unsymmetrical 1,6-Diene / $\gamma$-Lactam / 5Membered Ring / Copolymerization /

In the cyclopolymerization of unconjugated 1,6-dienes, enhancement of cyclopolymerization for compounds containing vinyl moieties which do not homopolymerize well, has been examined for a number of monomers. They are $N, N$-diallylammonium salts, ${ }^{1} N$-alkyl- $N$ allylmethacrylamides, ${ }^{2} \mathrm{~N}$-alkyldimethacrylamides, ${ }^{3}$ diallyl ether, diallylamine, diallylmalonic acid and related monomers. ${ }^{4}$

In view of the high homopolymerizability of $N, N$-disubstituted acrylamides, ${ }^{5}$ polymerization of $\mathrm{N}$-alkyl- $\mathrm{N}$-allylacrylamides as unsymmetrical unconjugated 1,6-dienes will proceed to give polymers having the structural unit of $N, N$-disubstituted acrylamide. Kodaira and
Sumiya $^{6}$ have studied the mechanism of cyclopolymerization of $N$-methyl- $N$-allylacrylamide (MAA) and identified the radicals by ESR measurements. They showed that MAA was incorporated into the polymer exclusively through its acryloyl group and the rate determining step in the cyclopolymerization was the reaction of intramolecular cyclization. In this connection, we are interested in the effects of $\mathrm{N}$-substituents on the rate of intramolecular cyclization, i.e., on the degree of cyclization in the cyclopolymerization of $\mathrm{N}$ alkyl- $N$-allylacrylamides. This article describes the free-radical cyclopolymerization of $\mathrm{N}$ butyl- $N$-allylacrylamide (BAA) and $N$-octyl- 
$N$-allylacrylamide (OAA) along with MAA. The degree of cyclization increases not only with decrease in the monomer concentration but also with increase in the chain length of $N$ alkyl groups. A mechanism of cyclopolymerization is proposed for interpretation of the results.

\section{EXPERIMENTAL}

\section{Materials}

The secondary amines, $N$-methylallylamine, ${ }^{7} \quad N$-butylallylamine, ${ }^{8} \quad N$-butylpropylamine, ${ }^{9}$ and $N$-octylpropylamine, ${ }^{10}$ were prepared according to the literature. $N$-Octylallylamine was prepared by the reaction of allylamine and octyl bromide according to the procedure for $\mathrm{N}$-octylpropylamine in $84 \%$ yield; bp $100^{\circ} \mathrm{C} / 11 \mathrm{mmHg}(1 \mathrm{mmHg}=$ 133.22 Pa). Acryloyl chloride was prepared by the reaction of acrylic acid and benzoyl chloride.

Solvents and an initiator were commercial products and purified in the usual methods. The other reagents were used as received.

\section{Monomers}

$N$-Alkyl- $N$-allylacrylamides were prepared by reactions of acryloyl chloride with $N$ alkylallylamines. A typical run was carried out in a $1 \mathrm{dm}^{3}$ four necked flask equipped with a stirrer, a dropping funnel, a reflux condenser and a thermometer. Into this flasky, Nalkylallylamine $\quad(0.5 \mathrm{~mol}), \quad$ triethylamine $(0.5 \mathrm{~mol})$ and benzene $\left(0.5 \mathrm{dm}^{3}\right)$ were placed, and acryloyl chloride $(0.5 \mathrm{~mol})$ was added dropwise at $0-5^{\circ} \mathrm{C}$ during $4 \mathrm{~h}$. The reaction mixture was stirred at ambient temperature for more $2 \mathrm{~h}$. It was filtered to remove the salt and the filtrate was condensed by evaporating the solvent. The condensed solution was washed with dilute hydrochloric acid $\left(2 \mathrm{~mol} \mathrm{dm}^{-3}\right)$, aqueous sodium hydrogencarbonate $(5 \%)$ and water succesively, and dried over sodium sulfate. Distillation gave each monomer.

$N$-Methyl- $N$-allylacrylamide (MAA) was given in $53 \%$ yield: bp $59.5^{\circ} \mathrm{C} / 0.8 \mathrm{mmHg}$ $\left(59^{\circ} \mathrm{C} / 1 \mathrm{mbar}\right)^{6}$; IR (neat) $1650(\mathrm{C}=\mathrm{O}), 1640$ (allyl $\mathrm{C}=\mathrm{C}$ ), 1610 (acryloyl $\mathrm{C}=\mathrm{C}$ ), 925 (allyl $\mathrm{C}=\mathrm{C}-\mathrm{H}$ ), and $795 \mathrm{~cm}^{-1}$ (acryloyl $\mathrm{C}=\mathrm{C}-$ $\mathrm{H}) ;{ }^{1} \mathrm{H} \mathrm{NMR}\left(\mathrm{CCl}_{4}\right) \delta 6.35-5.00(\mathrm{~m}, 6 \mathrm{H}, \mathrm{ac}-$ ryloyl and allyl protons), $3.96\left(\mathrm{~d}, 2 \mathrm{H}, \mathrm{NCH}_{2}\right)$, and $3.00 \mathrm{ppm}\left(\mathrm{s}, 3 \mathrm{H}, \mathrm{CH}_{3}\right)$.

$N$-Butyl- $N$-allylacrylamide (BAA) was given in $62 \%$ yield: bp $66.0^{\circ} \mathrm{C} / 0.25 \mathrm{mmHg}$; IR (neat) $1650(\mathrm{C}=\mathrm{O}), 1640$ (allyl $\mathrm{C}=\mathrm{C}), 1613$ (acryloyl $\mathrm{C}=\mathrm{C}$ ), 920 (allyl $\mathrm{C}=\mathrm{C}-\mathrm{H}$ ), and $795 \mathrm{~cm}^{-1}$ (acryloyl C=C-H); ${ }^{1} \mathrm{H}$ NMR $\left(\mathrm{CCl}_{4}\right) \delta 6.49$ $4.96(\mathrm{~m}, 6 \mathrm{H}$, acryloyl and allyl protons), 3.98 (d, $\left.2 \mathrm{H}, \mathrm{NC}_{2} \mathrm{CH}\right), 3.32\left(\mathrm{t}, 2 \mathrm{H}, \mathrm{NC}_{2} \mathrm{CH}_{2}\right.$ ), and $1.45-0.96 \mathrm{ppm}\left(\mathrm{m}, 7 \mathrm{H}, \mathrm{CH}_{2} \mathrm{CH}_{2} \mathrm{CH}_{3}\right)$; MS (70 eV) $m / z(\%) 167$ (5), 166 (3), 124 (34), 70 (93), 54 (100), and 41 (33).

$\mathrm{N}$-Octyl- $\mathrm{N}$-allylacrylamide (OAA) was obtained in $46^{\circ} \%$ yield: bp $89.0^{\circ} \mathrm{C} / 0.03 \mathrm{mmHg}$; IR (neat) $1650(\mathrm{C}=\mathrm{O}), 1640$ (allyl $\mathrm{C}=\mathrm{C}$ ), 1610 (acryloyl $\mathrm{C}=\mathrm{C}$ ), 920 (allyl $\mathrm{C}=\mathrm{C}-\mathrm{H}$ ), and $790 \mathrm{~cm}^{-1}$ (acryloyl C=C-H); ${ }^{1} \mathrm{H}$ NMR $\left(\mathrm{CCl}_{4}\right)$ $\delta 6.40-4.90(\mathrm{~m}, 6 \mathrm{H}$, acryloyl and allyl protons), 3.98 (d, 2H, $\left.\mathrm{NCH}_{2} \mathrm{CH}\right), 3.23(\mathrm{t}, 2 \mathrm{H}$, $\left.\mathrm{NCH}_{2} \mathrm{CH}_{2}\right)$, and $1.57-0.92 \mathrm{ppm}(\mathrm{m}, 15 \mathrm{H}$, $\left.\left(\mathrm{CH}_{2}\right)_{6} \mathrm{CH}_{3}\right) ; \mathrm{MS}(70 \mathrm{eV}) \mathrm{m} / z(\%) 224$ (3), 223 (3), 124 (64), 70 (100), 55 (97), 41 (40), and 28 (59).

Monomers having one of the functional groups of dienes were prepared by the same procedure as for the diene monomers.

$N$-Butyl- $N$-propylacrylamide (BPA) $(40 \%$ yield): bp $70^{\circ} \mathrm{C} / 0.2 \mathrm{mmHg}$; IR (neat) 1650 $(\mathrm{C}=\mathrm{O}), 1612$ and $795 \mathrm{~cm}^{-1}(\mathrm{C}=\mathrm{C}$ and $\mathrm{C}=\mathrm{C}-$ $\mathrm{H}) ;{ }^{1} \mathrm{H}$ NMR $\left(\mathrm{CCl}_{4}\right) \delta 6.50-5.40(\mathrm{~m}, 3 \mathrm{H}$, $\left.\mathrm{C} \underline{\mathrm{H}}=\mathrm{C}_{2}\right), 3.27\left(\mathrm{~m}, 4 \mathrm{H}, \mathrm{NCH}_{2}\right), 1.38(\mathrm{~m}, 6 \mathrm{H}$, $\left.\mathrm{CH}_{2}\right)$, and $0.88 \mathrm{ppm}\left(\mathrm{m}, 6 \mathrm{H}, \mathrm{CH}_{2}\right) ; \mathrm{MS}(70 \mathrm{eV})$ $m / z(\%) 169(7), 140(23), 126(26), 86(57), 72$ (76), 55 (100), and 41 (16).

$N$-Butyl- $N$-allylpropionamide (BAP) $(45 \%$ yield): bp $65^{\circ} \mathrm{C} / 0.2 \mathrm{mmHg}$; IR (neat) 1652 $(\mathrm{C}=\mathrm{O}), \quad 1645$ and $920 \mathrm{~cm}^{-1} \quad(\mathrm{C}=\mathrm{C}$ and $\mathrm{C}=\mathrm{C}-\mathrm{H}) ;{ }^{1} \mathrm{H}$ NMR $\left(\mathrm{CCl}_{4}\right) \delta 5.23(\mathrm{~m}, 3 \mathrm{H}$, $\left.\mathrm{C} \underline{\mathrm{H}}=\mathrm{CH}_{2}\right), 3.92\left(\mathrm{~d}, 2 \mathrm{H}, \mathrm{NCH}_{2} \mathrm{CH}\right), 3.28(\mathrm{t}$, $\left.2 \mathrm{H}, \mathrm{NCH}_{2} \mathrm{CH}_{2}\right), 2.28\left(\mathrm{q}, 2 \mathrm{H}, \mathrm{C}(=\mathrm{O}) \mathrm{CH}_{2}\right)$, and $1.42-0.93 \mathrm{ppm}\left(\mathrm{m}, 10 \mathrm{H}, \mathrm{CH}_{2}\right.$ and $\left.\mathrm{CH}_{3}\right)$; 
MS (70 eV) $m / z(\%) 169$ (4), 70 (100), 57 (32), and 41 (28).

$N$-Octyl- $N$-propylacrylamide (OPA) $\quad(45 \%$ yield): bp $92^{\circ} \mathrm{C} / 0.05 \mathrm{mmHg}$; IR (neat) 1650 $(\mathrm{C}=\mathrm{O}), \quad 1615$ and $795 \mathrm{~cm}^{-1} \quad(\mathrm{C}=\mathrm{C}$ and $\mathrm{C}=\mathrm{C}-\mathrm{H}) ;{ }^{1} \mathrm{H}$ NMR $\left(\mathrm{CCl}_{4}\right) \delta 6.33-5.25(\mathrm{~m}$, $\left.3 \mathrm{H}, \mathrm{CH}=\mathrm{CH}_{2}\right), 3.18\left(\mathrm{t}, 4 \mathrm{H}, \mathrm{NC}_{2}\right)$, and $1.47-0.78 \mathrm{ppm}\left(\mathrm{m}, 20 \mathrm{H}, \mathrm{CH}_{2}\right.$ and $\left.\mathrm{CH}_{3}\right) ; \mathrm{MS}$ $(70 \mathrm{eV}) \mathrm{m} / \mathrm{z}(\%) 225(8), 126(84), 73(100)$, and 55 (86).

$N$-Octyl- $N$-allylacetamide $\quad(\mathrm{OAC}) \quad(74 \%$ yield): bp $92^{\circ} \mathrm{C} / 0.08 \mathrm{mmHg}$; IR (neat) 1655 $(\mathrm{C}=\mathrm{O}), 1640$ and $920 \mathrm{~cm}^{-1}(\mathrm{C}=\mathrm{C}$ and $\mathrm{C}=\mathrm{C}-$ $\mathrm{H}) ;{ }^{1} \mathrm{H}$ NMR $\left(\mathrm{CCl}_{4}\right) \delta 5.25(\mathrm{~m}, 3 \mathrm{H}, \mathrm{CH}=$ $\left.\mathrm{CH}_{2}\right), 3.87\left(\mathrm{~d}, 2 \mathrm{H}, \mathrm{NCH}_{2} \mathrm{CH}\right), 3.20(\mathrm{t}, 2 \mathrm{H}$, $\left.\mathrm{NC}_{2} \mathrm{CH}_{2}\right), 1.95\left(\mathrm{~s}, 3 \mathrm{H}, \mathrm{C}(=\mathrm{O}) \mathrm{CH}_{3}\right), 1.30$ (s, $12 \mathrm{H}, \mathrm{CH}_{2}$ ), and $0.87 \mathrm{ppm}\left(\mathrm{t}, 3 \mathrm{H}, \mathrm{CH}_{3}\right) ; \mathrm{MS}$ $(70 \mathrm{eV}) \mathrm{m} / \mathrm{z}(\%) 212$ (3). 112 (15), 70 (100), 43 (25), and 41 (29).

The monomers were distilled prior to use until their purity became above $99 \%$ as determined by GLC.

\section{Polymerization}

Polymerization was carried out in a sealed tube using AIBN as the initiator and benzene or dioxane as the solvent. The sealed tubes were prepared by repeating usual freeze-thaw cycles and allowed to polymerize in an incubator maintained at $60^{\circ} \mathrm{C}$. The reaction mixtures were poured into petroleum ether for poly(MAA) and poly(BAA), and into methanol for poly(OAA). The separated polymers were freeze-dried from their benzene solutions.

Poly(MAA) was prepared at $[\mathrm{M}]_{0}=0.51$ mol dm ${ }^{-3}$ and $[\mathrm{AIBN}]_{0}=2.53 \times 10^{-3} \mathrm{~mol}$ $\mathrm{dm}^{-3}$ in benzene; IR (film) 1685 (sh), 1680 $\left(\mathrm{C}=\mathrm{O}\right.$ ), 1633 and $920 \mathrm{~cm}^{-1}$ (allyl $\mathrm{C}=\mathrm{C}$ and $\mathrm{C}=\mathrm{C}-\mathrm{H}) ;{ }^{1} \mathrm{H} \mathrm{NMR}\left(\mathrm{CDCl}_{3}, 60^{\circ} \mathrm{C}\right) \delta 5.80-$ $5.19\left(\mathrm{~m}, 1.24 \mathrm{H}\right.$, allyl $\left.\mathrm{CH}=\mathrm{CH}_{2}\right)$ and 4.00 $1.48 \mathrm{ppm}(\mathrm{m}, 9.76 \mathrm{H}$, the other protons). The mole fraction of allyl groups $\left(f_{\mathrm{A}}\right)$ was calculated from the ratio of integrated ${ }^{1} \mathrm{H}$ NMR signals to be 0.41 . The value of $f_{\mathrm{A}}$ was also determined by the titrimetric method to be
0.47 . The reduced viscosity of the polymer was $0.31 \mathrm{dlg}^{-1}$ measured on a $0.20-\mathrm{g} \mathrm{dl}^{-1}$ benzene solution at $30^{\circ} \mathrm{C}$.

Poly(BAA) was prepared at $[\mathrm{M}]_{0}=0.50 \mathrm{~mol}$ $\mathrm{dm}^{-3}$ and $[\mathrm{AIBN}]_{0}=2.53 \times 10^{-3} \mathrm{~mol} \mathrm{dm}^{-3}$ in benzene; IR (film) 1690 (sh), $1680(\mathrm{C}=\mathrm{O})$, 1635 and $920 \mathrm{~cm}^{-1}$ (allyl $\mathrm{C}=\mathrm{C}$ and $\left.\mathrm{C}=\mathrm{C}-\mathrm{H}\right)$; ${ }^{1} \mathrm{H}$ NMR $\left(\mathrm{CDCl}_{3}, 60^{\circ} \mathrm{C}\right) \delta 5.68-5.03(\mathrm{~m}$, $0.93 \mathrm{H}$, allyl $\left.\mathrm{CH}=\mathrm{CH}_{2}\right)$ and $3.94-0.93(\mathrm{~m}$, $16.05 \mathrm{H}$, the other protons). $f_{\mathrm{A}}$ was calculated to be 0.32 from the ratio of ${ }^{1} \mathrm{H}$ NMR signals. The value of $f_{\mathrm{A}}$ was also determined to be 0.34 by the titrimetric method. The reduced viscosity of this polymer was $0.47 \mathrm{dlg}^{-1}$ measured on a $0.20-\mathrm{g} \mathrm{dl}^{-1}$ benzene solution at $30^{\circ} \mathrm{C}$.

Poly(OAA) was prepared at $[\mathrm{M}]_{0}=0.50$ mol dm ${ }^{-3}$ and $[A I B N]_{0}=2.50 \times 10^{-3} \mathrm{~mol} \mathrm{dm}^{-3}$ in benzene; IR (film) 1693 (sh), $1683(\mathrm{C}=\mathrm{O})$, 1640 and $920 \mathrm{~cm}^{-1}($ allyl $\mathrm{C}=\mathrm{C}$ and $\mathrm{C}=\mathrm{C}-\mathrm{H})$; ${ }^{1} \mathrm{H}$ NMR $\left(\mathrm{CDCl}_{3}, 60^{\circ} \mathrm{C}\right) \delta 5.65-5.03(\mathrm{~m}$, $0.82 \mathrm{H}$, allyl $\left.\mathrm{C} \underline{\mathrm{H}}=\mathrm{CH}_{2}\right)$ and $3.92-0.93(\mathrm{~m}$, $24.18 \mathrm{H}$, the other protons). $f_{\mathrm{A}}$ was calculated to be 0.27 from the ratio of integrated ${ }^{1} \mathrm{H}$ NMR signals. The value of $f_{\mathrm{A}}$ was also determined to be 0.27 by the titrimetric method. The reduced viscosity of poly(OAA) prepared at $[\mathrm{M}]_{0}=0.30$ and $[\mathrm{AIBN}]_{0}=2.50 \times 10^{-3}$ mol dm ${ }^{-3}$ was $0.37 \mathrm{dl} \mathrm{g}^{-1}$ measured on a 0.20 $\mathrm{g} \mathrm{dl}^{-1}$ benzene solution at $30^{\circ} \mathrm{C}$.

\section{Copolymerization}

This was carried out in a manner similar to that for homopolymerization. Copolymer composition was determined by analyzing the unreacted monomers with GLC in the presence of tetradecane as internal standard.

\section{Measurements}

The mole fraction of residual allyl groups in the polymer, $f_{\mathrm{A}}$, was measured by the titrimetric method using mercury (II) acetate, ${ }^{11}$ where the reaction was carried out for $4 \mathrm{~h}$, while the reaction with monomers was completed in $20-30$ minutes. IR spectra were recorded on a Shimadzu IR-400 spectrometer. ${ }^{1} \mathrm{H}$ NMR spec- 
tra of monomers were recorded on a Nippon Denshi JNM-PMX60 spectrometer and those of polymers were recorded on a Nippon Denshi JEOL FX-90Q spectrometer. Mass spectra were recorded on a Hitachi mass spectrometer RMU-7M at $70 \mathrm{eV}$.

GLC analyses were carried out on a Shimadzu GC-6A gas chromatograph fitted with an SF-96 column at $180^{\circ} \mathrm{C}$.

\section{RESULTS AND DISCUSSION}

\section{Polymerization Behavior}

Figure 1 shows time-conversion curves for the polymerization of MAA, BAA, and OAA at the initial monomer concentration of 0.50 mol dm ${ }^{-3}$ and the initial AIBN concentration of $2.53 \times 10^{-3} \mathrm{~mol} \mathrm{dm}^{-3}$ in benzene at $60^{\circ} \mathrm{C}$. The soluble polymers were obtained below conversions of $60 \%$ for both MAA and BAA and the poly(OAA) obtained at $86 \%$ conversion was still soluble. The polymerization with higher monomer concentrations than 1.0 moldm ${ }^{-3}$ gave soluble polymers when the conversion was lower than $20 \%$.

Figure 2 shows the effects of initial concentrations of monomers and AIBN on the overall rate of polymerization $R_{\mathrm{p}}$. The results gave the following relationships.

$$
\begin{aligned}
& R_{\mathrm{p}} \propto[\mathrm{MAA}]_{0}^{1.14}[\mathrm{AIBN}]_{0}^{0.73} \\
& R_{\mathrm{p}} \propto[\mathrm{BAA}]_{0}^{1.17}[\mathrm{AIBN}]_{0}^{0.72} \\
& R_{\mathrm{p}} \propto[\mathrm{OAA}]_{0}^{1.32}[\mathrm{AIBN}]_{0}^{0.75}
\end{aligned}
$$

The order of reaction with respect to the concentration of each monomer is slightly higher than that of normal kinetics. This may be interpreted in terms of increase in viscosity of the polymerization mixtures as was reported by Kodaira and Sumiya ${ }^{6}$ for the polymerization of MAA in acetone. The kinetic orders with respect to the initiator concentration were a little higher than the square roots. The results suggest that bimolecular termination is accompanied by unimolecular termination such as a degradative chain transfer to allyl

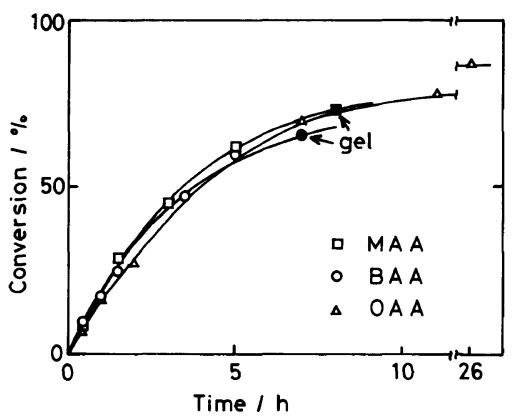

Figure 1. Time-conversion curves for the polymerization of $\mathrm{N}$-alkyl- $\mathrm{N}$-allylacrylamides initiated by AIBN at $60^{\circ} \mathrm{C}$ in benzene. $\square, \square,[\mathrm{MAA}], 0.51 \mathrm{moldm}^{-3} ; \bigcirc$, , [BAA], $0.50 \mathrm{~mol} \mathrm{dm}^{-3} ; \triangle$, [OAA], $0.50 \mathrm{~mol} \mathrm{dm}^{-3}$; [AIBN], $2.5 \times 10^{-3} \mathrm{~mol} \mathrm{dm}^{-3}$; gelation was observed at closed points.

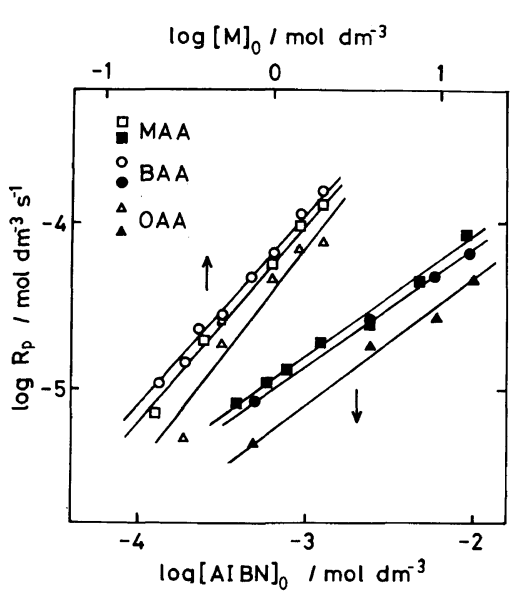

Figure 2. Relationships between $R_{\mathrm{p}}$ and monomer or initiator concentration. $\square$, MAA, $\mathbf{O}, \mathrm{BAA}, \triangle, \mathrm{OAA}$, $[\mathrm{M}], 0.50 \mathrm{moldm}^{-3} ; \square$, MAA, $\bigcirc$, BAA, $\triangle$, OAA, [AIBN], $2.5 \times 10^{-3} \mathrm{~mol} \mathrm{dm}^{-3}$; solvent, benzene; temp, $60^{\circ} \mathrm{C}$.

groups.

\section{Characterization of Polymers}

${ }^{1} \mathrm{H}$ NMR spectrum of poly(MAA) was almost the same as that reported by Kodaira and Sumiya. ${ }^{6}$ Figure 3 shows ${ }^{1} \mathrm{H}$ NMR spectra of poly(BAA) and poly(OAA) along with those of monomers. While the signals attributed to allyl protons were observed in the ${ }^{1} \mathrm{H}$ NMR spectra of both polymers, no signals due to acryloyl protons were observed. Figure 4 


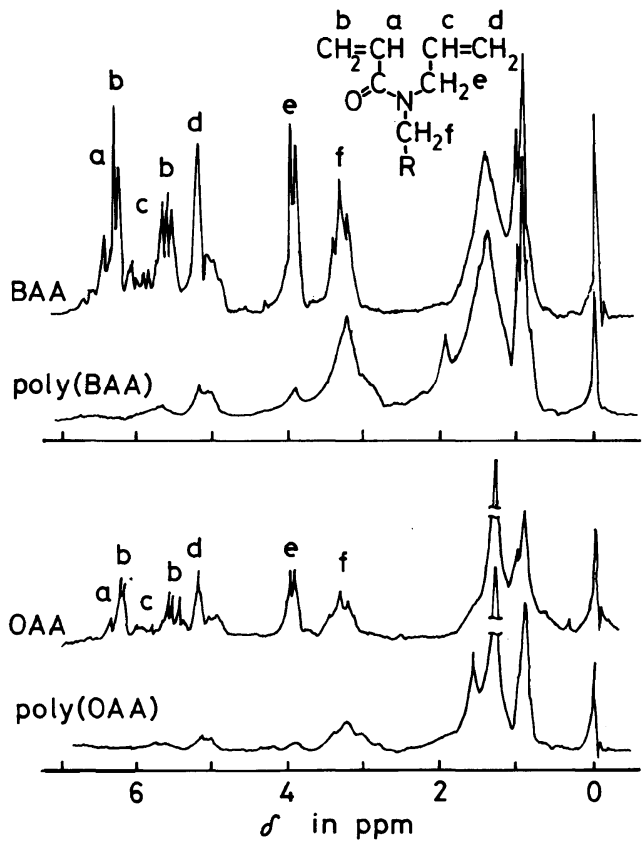

Figure 3. ${ }^{1} \mathrm{H}$ NMR spectra of monomers (BAA, OAA) in $\mathrm{CCl}_{4}$ and their polymers in $\mathrm{CDCl}_{3}$ at $60^{\circ} \mathrm{C}$. Polymerization conditions: [M], $0.50 \mathrm{~mol} \mathrm{dm}^{-3}$; [AIBN], $2.5 \times 10^{-3} \mathrm{moldm}^{-3}$; solvent, benzene; temp, $60^{\circ} \mathrm{C}$; time, $5 \mathrm{~h}$ for BAA and $4 \mathrm{~h}$ for OAA.

shows IR spectra of poly(BAA) and poly(OAA) along with those of the monomers. No absorption bands due to acryloyl groups were observed in the IR spectra of either polymer. These results suggest that the polymers have only the allyl groups as residual carbon-carbon double bonds.

Five-membered lactam was proposed to be present in the poly(MAA) as a cyclic unit. ${ }^{6}$ Similarly, cyclic units in both poly(BAA) and poly(OAA) are identified as the 5-membered ring since their IR absorption bands due to the stretching vibration of carbonyl groups appear in the range of $1693-1680 \mathrm{~cm}^{-1}$. No carbonyl absorptions due to 6-membered rings could be detected in the range of $1670-1650 \mathrm{~cm}^{-1}$. In the IR spectra of three diene polymers, the carbonyl absorptions due to the pendent amide units are considered to overlap with allyl absorption bands appearing in the range of $1640-1633 \mathrm{~cm}^{-1}$. Actually, the carbonyl ab- sorption due to the pendent amide units was observed at $1643 \mathrm{~cm}^{-1}$ in the IR spectrum of poly(OPA) which was the polymer of the mono-olefin having an acryloyl moiety of OAA. The results suggest that the polymers consist of the 5-membered ring unit, 1 , and the linear unit, 2, having a pendent $N$-allylamide group.<smiles>[R]N1CC(C[CH])C(CC)C1=O</smiles><smiles>[R]N(CC=C)C(=O)CC</smiles>

$\mathbf{a}: \mathrm{R}=\mathrm{CH}_{3}, \mathbf{b}: \mathrm{R}=\mathrm{C}_{4} \mathrm{H}_{9}, \mathbf{c}: \mathrm{R}=\mathrm{C}_{8} \mathrm{H}_{17}$

Copolymerization of Mono-olefins Having the Functional Group of Diene Monomers

Copolymerization of $N$-butyl- $N$-propylacrylamide (BPA) with $N$-butyl- $N$-allylpropionamide (BAP) as model compounds of BAA and that of $N$-octyl- $N$-propylacrylamide (OPA) with $N$-octyl- $N$-allylacetamide (OAC) as model compounds of OAA were carried out to see if the allyl moiety could be polymerized in the presence of acryloyl moiety. Figure 5 shows the copolymer compositions as a function of comonomer composition. Although the experimental plots show some scattering, the reactivity of acryloyl moieties is significantly higher than that of the allyl moieties. The monomer reactivity ratios derived by the curve fitting method are $r_{1}=35$ and $r_{2}=0.3$ for BPA $\left(\mathrm{M}_{1}\right)$ and $\operatorname{BAP}\left(\mathrm{M}_{2}\right)$, and $r_{1}=50$ and $r_{2}=0.013$ for OPA $\left(\mathrm{M}_{1}\right)$ and OAC $\left(\mathrm{M}_{2}\right)$, respectively.

\section{Cyclopolymerization Mechanism}

The results of both the polymer character- 


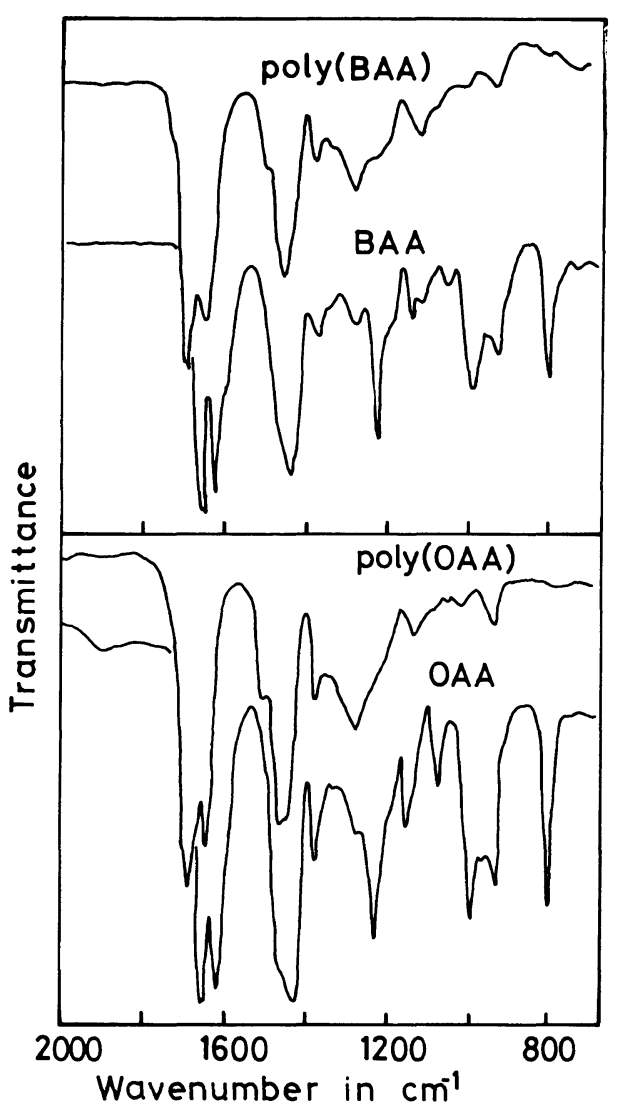

Figure 4. IR spectra of neat monomers (BAA, OAA) and their polymers measured on films. Polymerization conditions are the same as in Figure 3.

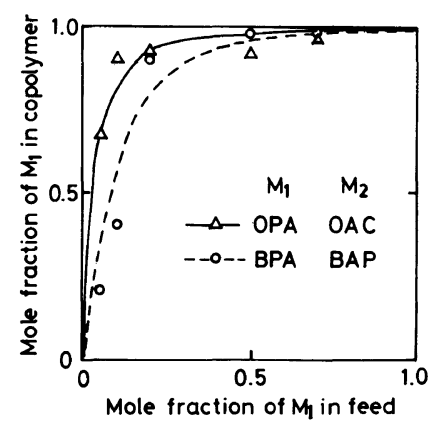

Figure 5. Composition diagrams for the copolymerization of mono-olefins having a counterpart of $N$-alkyl$N$-allylacrylamides. $\triangle$, OPA $\left(\mathrm{M}_{1}\right)-\mathrm{OAC}\left(\mathrm{M}_{2}\right),-$, calculated curve for $r_{1}=50, r_{2}=0.013$; $O$, BPA $\left(\mathrm{M}_{1}\right)$-BAP $\left(\mathrm{M}_{2}\right), \quad---$, calculated curve for $r_{1}=35, r_{2}=0.3$. Copolymerization conditions: $\left[\mathbf{M}_{1}+\mathbf{M}_{2}\right], 1.0 \mathrm{moldm}^{-3}$; [AIBN], $2.5 \times 10^{-3} \mathrm{~mol} \mathrm{dm}^{-3}$; solvent, benzene; temp, $60^{\circ} \mathrm{C}$.

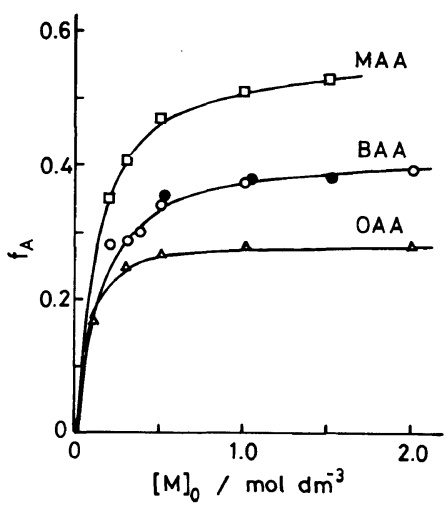

Figure 6. Mole fraction of the residual allyl groups in the polymers, $f_{\mathrm{A}}$, as a function of the initial monomer concentration. $\square$, MAA; $\bigcirc, \bigcirc$, BAA; $\triangle$, OAA. Polymerization conditions: [AIBN], $2.5 \times 10^{-3} \mathrm{~mol}$ $\mathrm{dm}^{-3}$; solvent, benzene (open plots), dioxane (closed plots); temp, $60^{\circ} \mathrm{C}$.

ization and the copolymerization suggest that the propagation proceeds intermolecularly between the polymer radicals and acryloyl groups of monomers and intramolecularly between the growing acryloyl radical and pendent allyl group of the terminal unit. Figure 6 shows the effects of the initial monomer concentration, $[\mathbf{M}]_{0}$, on the mole fraction of residual allyl groups in the polymer, $f_{\mathrm{A}}$. An increase in $f_{\mathbf{A}}$ with increasing $[\mathbf{M}]_{0}$ was observed, but it appeared to level off at $[\mathrm{M}]_{0}$ higher than $1.0 \mathrm{~mol} \mathrm{dm}^{-3}$. The degree of cyclization, $f_{\mathrm{C}}=1-f_{\mathrm{A}}$, increased in the order: poly(MAA) $<\operatorname{poly}($ BAA) $<$ poly(OAA). In other words, the cyclopolymerizability of $\mathrm{N}$-alkyl$\mathrm{N}$-allylacrylamides is enhanced by increase in the chain length of the $\mathrm{N}$-alkyl group in it.

In order to elucidate the dependence of both initial monomer concentration and $\mathrm{N}$-alkyl substituent on the degree of cyclization, two conformational isomers in either the monomers or growing acryloyl radicals are considered. LaPlanche and Rogers ${ }^{12}$ have reported that the preferred conformation in the unsymmetrically disubstituted acetamides and isobutyramides was an isomer in which the bulkier group was cis to the carbonyl oxygen atom. An attempt was made to determine a 
coalescence temperature of the rotational isomers of BAA around $\mathrm{C}(=\mathrm{O})-\mathrm{N}$ bond. Inspection of signals for $\mathrm{N}-\mathrm{CH}_{2}-\mathrm{CH}_{2}$ protons in the ${ }^{1} \mathrm{H}$ NMR spectra of BAA monomer at various temperatures indicated that the coalescence temperature of BAA is lower than room<smiles>[R]C(CC=C)C(=O)CC</smiles>

It can be assumed that while the $\mathrm{C}(=\mathrm{O})-N$ trans-allyl isomer $\left(\mathrm{P}_{\mathrm{t}} \cdot\right)$ exclusively cyclized to give an exo-cyclic radical $(\mathrm{P} \cdot)$, the $\mathrm{C}(=\mathrm{O})-N$ - temperature. Therefore, the rotational isomers of BAA could not be distinguished from each other at the polymerization temperature. As a result, the growing acryloyl radicals may consist of two conformational isomers as follows:<smiles>[R7]C(CC)C(=O)N([R])CC=C</smiles>

cis-allyl isomer $\left(\mathrm{P}_{\mathrm{c}} \cdot\right)$ adds to monomers to give a linear unit (L) and the growing acryloyl radical $\left(P_{t} \cdot\right.$ or $\left.P_{c} \cdot\right)$.<smiles>[Z]C1CN([R])C(=O)C1CC</smiles>

Alternatively, isomerization of the growing cis radical $P_{c} \cdot$ may occur to give the growing trans-radical $P_{t} \cdot$ which is subject to successive cyclization.

The suggested elementary reactions of propagation are shown in eq $1-6$.

$$
\begin{aligned}
& \mathrm{P}_{\mathrm{t}} \cdot \stackrel{k_{\mathrm{c}}}{\longrightarrow} \mathrm{P} . \\
& \mathrm{P}_{\mathrm{c}} \cdot \stackrel{k_{\mathrm{i}}}{\longrightarrow} \mathrm{P}_{\mathrm{t}} \cdot \\
& \mathrm{P}_{\mathrm{c}} \cdot+\mathrm{M} \stackrel{k_{\mathrm{p}}^{\prime} x}{\longrightarrow} \mathrm{P}_{\mathrm{t}} \cdot \\
& \mathrm{P}_{\mathrm{c}} \cdot+\mathrm{M} \stackrel{k_{\mathrm{p}}^{\prime}(1-x)}{\longrightarrow} \mathrm{P}_{\mathrm{c}} . \\
& \mathrm{P} \cdot+\mathrm{M} \stackrel{k_{\mathrm{p}} x}{\longrightarrow} \mathrm{P}_{\mathrm{t}} \cdot \\
& \mathrm{P} \cdot+\mathrm{M} \stackrel{k_{\mathrm{p}}(1-x)}{\longrightarrow} \mathrm{P}_{\mathrm{c}} .
\end{aligned}
$$

where $k_{\mathrm{c}}, k_{\mathrm{i}}, k_{\mathrm{p}}^{\prime}$, and $k_{\mathrm{p}}$ are the rate constants for the intramolecular cyclization of the radi- cal $P_{t} \cdot$, the isomerization of the rdical $P_{c} \cdot$ to the radical $P_{t} \cdot$, the addition of the radical $P_{c}$. to the monomer, and the addition of the radical $\mathbf{P} \cdot$ to the monomer, respectively, and $x$ is the fraction of the intermolecular propagation which gives the growing trans acryloyl radical $P_{t}$.

Assuming a constant ratio of $\left[\mathrm{P}_{\mathrm{t}} \cdot\right] /\left[\mathrm{P}_{\mathrm{c}} \cdot\right]=$ $x /(1-x)=K$ and a stationary state for each radical, the ratio of the mole fraction of the cyclic unit $f_{\mathrm{C}}$ over the linear unit $f_{\mathrm{A}}$ is given in eq 7 :

$$
\frac{f_{\mathrm{C}}}{f_{\mathrm{A}}}=\frac{k_{\mathrm{c}}\left[\mathrm{P}_{t} \cdot\right]}{k_{\mathrm{p}}^{\prime}\left[\mathrm{P}_{\mathrm{c}} \cdot\right][\mathrm{M}]}=\frac{k_{\mathrm{r}}(1+K)}{[\mathrm{M}]}+K
$$

where $k_{\mathrm{r}}=k_{\mathrm{i}} / k_{\mathrm{p}}^{\prime}$ is the ratio of the rate constants for the isomerization over the propagation of the radical $P_{c} \cdot$

When conversion of the monomer is low, the monomer concentration $[\mathrm{M}]$ in eq 7 can be replaced by that at the start $[\mathrm{M}]_{0}$. Figure 7 


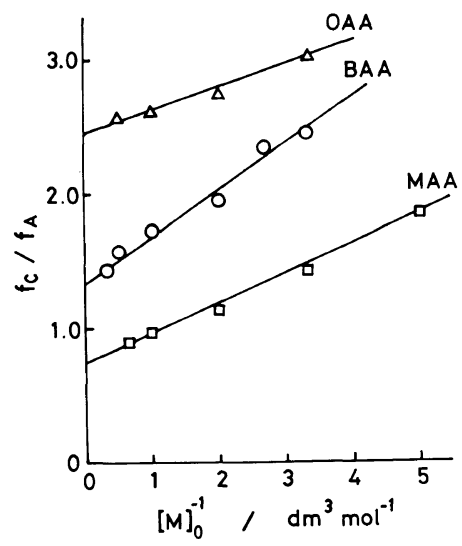

Figure 7. Relationship between the ratio of mole fractions of the cyclic units over the linear units, $f_{\mathrm{C}} / f_{\mathrm{A}}$, and the reciprocal of the initial monomer concentration, 1/[M] $]_{0}$. $\square$, MAA; O, BAA; $\triangle$, OAA. Polymerization conditions are the same as in Figure 6.

Table I. Cyclopolymerization parameters

\begin{tabular}{lccc}
\hline Monomer & $k_{\mathrm{r}}^{\mathrm{a}} / \mathrm{mol} \mathrm{dm}^{-3}$ & $K^{\mathrm{b}}$ & $x$ \\
\hline MAA & 0.13 & 0.73 & 0.42 \\
BAA & 0.14 & 1.33 & 0.57 \\
OAA & 0.05 & 2.46 & 0.71 \\
\hline
\end{tabular}

a $k_{\mathrm{r}}=k_{\mathrm{i}} / k_{\mathrm{p}}^{\prime}$ : the ratio of the rate constants for isomerization over the propagation of the radical $P_{c} \cdot$

b $K=x /(1-x)=\left[\mathrm{P}_{\mathrm{t}} \cdot\right] /\left[\mathrm{P}_{\mathrm{c}} \cdot\right]$

$\mathrm{P}_{t} \cdot$ and $\mathrm{P}_{\mathrm{c}} \cdot$ are the propagating acryloyl radicals of $\mathrm{C}(=\mathrm{O})-\mathrm{N}$-trans-allyl and $\mathrm{C}(=\mathrm{O})-\mathrm{N}$-cis-allyl, respectively.

shows plots of $f_{\mathrm{C}} / f_{\mathrm{A}}$ as a function of $1 /[\mathrm{M}]_{0}$ which give straight lines in the range of monomer concentration higher than 0.3 mol dm ${ }^{-3}$. The intercept and slope of each line give the values of $k_{\mathrm{r}}$ and $K$, respectively. Table I summarizes the parameters of cyclopolymerization. A comparison of the values of $x$ suggests that the effect of $\mathrm{N}$-alkyl substituents on cyclopolymerization is interpreted in terms of the difference in the ratio of the isomers of growing acryloyl radicals; the isomerization between these isomers may be insignificant compared with any other propagation reactions.

A modification of eq 7 gives eq 8 at low monomer conversion.

$$
f_{\mathrm{A}}=\frac{[\mathrm{M}]_{0}}{(1+K)\left(k_{\mathrm{r}}+[\mathrm{M}]_{0}\right)}
$$

The solid curves in Figure 6 show the calculated plots of $f_{\mathrm{A}}$ as a function of $[\mathrm{M}]_{0}$ according eq 8 where the values of $k_{\mathrm{r}}$ and $K$ in Table I are used. Agreement of these curves with the experimental plots is fairly good except at low monomer concentrations.

In conclusion, the difference in cyclopolymerizabilities of $N$-alkyl- $N$-allylacrylamides can be interpreted in terms of the effect of size of an $\mathrm{N}$-alkyl group. The longer the chain length of an $\mathrm{N}$-alkyl substituent in the monomer, the higher is its cyclopolymerizability. This may be due to the fact that the longer $\mathrm{N}$-alkyl substituent may facilitate favorable conformation of the growing acryloyl radical, i.e., $\mathrm{C}(=\mathrm{O})-\mathrm{N}$-trans-allyl isomer, for intramolecular cyclization.

\section{REFERENCES}

1. G. B. Butler and R. J. Angelo, J. Am. Chem. Soc., 79, 3128 (1957).

2. T. Kodaira, M. Ishikawa, and M. Murata, J. Polym. Sci., Polym. Chem. Ed., 14, 1107 (1976).

3. T. Kodaira and F. Aoyama, J. Polym. Sci., Polym. Chem. Ed., 12, 897 (1974).

4. D. H. Solomon, J. Macromol. Sci.-Chem., A9, 97 (1975); A. L. J. Beckwith, A. K. Ong, and D. H. Solomon, ibid., A9, 115, 125 (1975).

5. B. Yamada, M. Yoshikawa, and T. Otsu, J, Polym. Sci., Polym. Chem. Ed., 22, 463 (1984).

6. T. Kodaira and Y. Sumiya, Makromol. Chem., 187, 933 (1986).

7. A. L. Morrison and H. Rinderknecht, J. Chem. Soc., 1478 (1950).

8. W. B. Burnett, R. L. Jenkins, C. H. Peet, E. E. Dreger, and R. Adams, J. Am. Chem. Soc., 59, 2248 (1937).

9. K. N. Campbell, A. H. Sommers, and B. K. Campbell, J. Am. Chem. Soc., 66, 82 (1944).

10. G. F. Grail, L. E. Tenenbaum, A. V. Tolstooahov, C. J. Duca, J. F. Reinhard, F. E. Anderson, and J. V. Scudi, J. Am. Chem. Soc., 74, 1311 (1952).

11. M. N. Das, Anal. Chem., 26, 1086 (1954).

12. L. A. LaPlanche and M. T. Rogers, J. Am. Chem. Soc., 85, 3728 (1963). 